\title{
NGR-TNF, a novel vascular-targeting agent, does not induce cytokine recruitment of proangiogenic bone marrow-derived cells
}

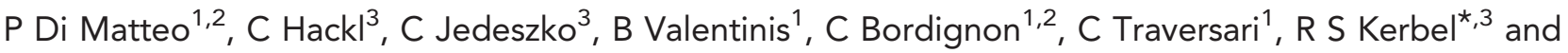 \\ G-P Rizzardi ${ }^{*} 1$ \\ ${ }^{1}$ MolMed SpA, Via Olgettina 58, 20132 Milan, Italy; ${ }^{2}$ Vita-Salute University, Via Olgettina 58, 20132 Milan, Italy and ${ }^{3}$ Department of \\ Medical Biophysics, Sunnybrook Research Institute, Sunnybrook Health Sciences Centre, Biological Sciences Platform, University \\ of Toronto, 2075 Bayview Avenue, M4N 3M5 Toronto, Ontario, Canada
}

Background: Administration of certain chemotherapy drugs at the maximum tolerated dose, vascular-disrupting agents (VDAs) and irradiation can induce mobilisation and tumour homing of proangiogenic bone marrow-derived cells (BMDCs). Increases in cytokines and chemokines contribute to such mobilisation that eventually promotes tumour (re)growth. NGR-TNF is a vascular-targeting agent in advanced clinical development, coupling the CNGRCG angiogenic vessel-homing peptide with tumour necrosis factor-alpha (TNF). We investigated whether NGR-TNF mobilises host BMDCs and growth factors.

Methods: Blood was obtained from Lewis lung carcinoma and 4T1 tumour-bearing mice at different time points following NGRTNF, VDA or anti-VEGFR2/flk-1 antibody treatment. Levels of circulating growth factors were assessed by ELISAs. BMDCs were characterised by FACS. Circulating endothelial progenitor cells were defined as $\mathrm{CD} 45^{-} / \mathrm{CD} 13^{+} / \mathrm{flk}-1^{+} / \mathrm{CD} 117^{+} / 7 \mathrm{AAD}{ }^{-}$, Tie2expressing monocytes as $\mathrm{CD} 45^{+} / \mathrm{CD} 11 \mathrm{~b}^{+} / \mathrm{Tie}^{+}$and myeloid-derived suppressor cells as $\mathrm{CD} 45^{+} / \mathrm{CD} 11 \mathrm{~b}^{+} / \mathrm{Gr} 1^{+}$cells.

Results: NGR-TNF decreases tumour blood vessel density-inducing apoptosis of tumour and tumour endothelial cells. Unlike VDAs, or high-dose NGR-TNF, lower doses of NGR-TNF, comparable to those used in clinical trials, neither mobilise nor recruit to the tumour site proangiogenic BMDCs or induce host growth factors.

Conclusion: Low-dose NGR-TNF exerts antitumour activity without inducing proangiogenic host responses, conceivably important for preventing/overcoming resistance and designing combination therapeutic strategies.

Currently, there are two main classes of vascular-targeting drugs used in oncology. The first (and main) class is comprised of antiangiogenic drugs, of which a number are thus far approved for clinical use in oncology, for example, bevacizumab, the humanised anti-VEGF monoclonal antibody, and sunitinib, sorafenib, axitinib and pazopanib, all oral small molecule tyrosine kinase inhibitors (TKIs), which target a number of TKIs including VEGF receptors. Registered indications, depending upon the drug, include renal cell cancer (sunitinib, pazopanib, sorafenib, axitinib and bevacizumab), hepatocellular carcinoma (sorafenib), pancreatic neuroendocrine tumours (sunitinib), medullary thyroid cancer (vandetanib), breast, ovarian, non-small cell lung and colorectal carcinomas (bevacizu$\mathrm{mab}$ ) and glioblastoma (bevacizumab) (see http://www.fda.gov). These approvals, especially for historically refractory cancers such as renal cell and hepatocellular carcinomas, represent a genuine breakthrough in medical oncology treatment. Nevertheless, the progression-free survival and overall survival (OS) benefits of these drugs, especially OS, when successful, remain modest.

Vascular-disrupting agents (VDAs) define the second class of vascular-targeting drugs. None of these is currently approved for 
clinical use, although there are more than 10 in various stages of clinical development (see http://www.clinicaltrials.gov). Unlike most neovasculature-targeting antiangiogenic drugs, VDAs directly target the established but abnormal tumour vasculature, causing their very rapid destruction, which leads to profound increases in tumour hypoxia and intra-tumoural necrosis. However, this potent effect is followed by rapid regrowth from the remaining viable tumour rim (Shaked et al, 2006).

In this context, NGR-TNF, a new drug generated by the fusion of the CNGRCG peptide to the N-terminal domain of human (h)TNF (Curnis et al, 2000), defines a new class of vasculartargeting agent. NGR-TNF is targeted to the tumour vasculature by the CNGRC peptide motif (Arap et al, 1998; Curnis et al, 2000) that specifically interacts with the CD13 (aminopeptidase N) expressed by endothelial cells of angiogenic vessels (Pasqualini et al, 2000; Curnis et al, 2002a; Buehler et al, 2006). NGR-TNF is able to control tumour growth in several tumour models, either alone or in combination with chemotherapeutics (Curnis et al, 2000; Sacchi et al, 2006; Gregorc et al, 2009; Santoro et al, 2010; Gregorc et al, 2010b, 2011). In preclinical models, it has been shown that the dose-response curve of NGR-TNF is bell shaped (Curnis et al, 2002b). As a matter of fact, NGR-murine(m)TNF has an antitumour effect at doses lower than $1 \mathrm{ng}$ per mouse or equal/ higher than $1 \mu \mathrm{g}$ per mouse. This is due to the induction of counter regulatory mechanisms, including TNF receptor shedding. At doses higher than $1 \mu \mathrm{g}$ per mouse, NGR-mTNF overcomes these negative feedback mechanisms and shows again its antitumour activity (Curnis et al, 2002b). In this context, NGR-mTNF showed a significant antitumour activity at very low doses ( $0.1 \mathrm{ng}$ per mouse, corresponding to $5 \mathrm{ng}$ per $\mathrm{kg}$ ) (Curnis et al, 2000), equivalent in humans to a dose of $0.2 \mu \mathrm{g} \mathrm{m}^{-2}$, which was the selected starting dose for phase I clinical development. Dose escalation studies have been performed without reaching a clear MTD (van Laarhoven et al, 2010; Zucali et al, 2013). However, it has been observed that the low dose of $0.8 \mu \mathrm{g} \mathrm{m}^{-2}$ has more pronounced antivascular effects than higher doses, and it was therefore considered as the optimal biological dose (Gregorc et al, 2010a). NGR-TNF at the low dose of $0.8 \mu \mathrm{g} \mathrm{m}^{-2}$ is currently being tested in several phase II and III clinical trials with promising phase II results (Gregorc et al, 2009; Santoro et al, 2010; Gregorc et al, 2010a, b, 2011).

Bone marrow-derived cells (BMDCs) play an important role in regulating angiogenesis during tumour progression. Over the last 15 years, a number of different subtypes of proangiogenic and protumourigenic BMDCs have been identified, including circulating endothelial progenitor cells (CEPs) (Lyden et al, 2001; Shaked et al, 2006), tumour-associated macrophages (Lin et al, 2006), Tie2-expressing monocytes (TEMs) (De Palma et al, 2003, 2005), dendritic cell precursors (Conejo-Garcia et al, 2004), mast cells

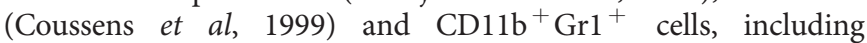
neutrophils (Nozawa et al, 2006) and myeloid-derived suppressor cells (MDSCs) (Yang et al, 2004; Shojaei et al, 2007). These various cell types are thought to promote tumour angiogenesis by several mechanisms, for example, by producing proangiogenic factors (Murdoch et al, 2008; Qian and Pollard, 2010), as well as by their differentiation into endothelial cells in the case of CEPs (Lyden et al, 2001; Shaked et al, 2006). In addition, it has been shown that several types of BMDCs, such as CEPs, TEMs or $\mathrm{CD}_{11 \mathrm{~b}}{ }^{+} \mathrm{Gr}{ }^{+}$ cells, are involved in the formation of 'premetastatic niches' (Kaplan et al, 2005; Gao et al, 2008; Gingis-Velitski et al, 2011). There is now evidence that treatment with VDAs (e.g., Oxi4503) or certain chemotherapeutic drugs administered at the maximum tolerated dose (e.g., paclitaxel, cyclophosphamide, 5-FU) or local irradiation can rapidly induce mobilisation and subsequent tumour homing of a number of different proangiogenic BMDCs (Shaked et al, 2006; Kerbel, 2008; Shaked et al, 2008; De Palma and Lewis, 2011; Denardo et al, 2011; Welford et al, 2011), exerting in some cases prometastatic effects (Gingis-Velitski et al, 2011). Induction of several host growth factors and chemokines, such as granulocyte colony-stimulating factor (G-CSF), stromal cell-derived factor-1 (SDF-1) and osteopontin (OPN), contributes to this drug-induced $\mathrm{BMDC}$ mobilisation and migration to the viable tumour rim that remains after treatment (Shaked et al, 2008, 2009; Welford et al, 2011). This process promoting angiogenesis and rapid tumour regrowth affects the overall antitumour activities of the aforementioned treatments (Shaked et al, 2008, 2009; De Palma and Lewis, 2011; Denardo et al, 2011; Welford et al, 2011).

Based on these observations, we decided to evaluate the impact of NGR-TNF on BMDC mobilisation and its effects on inducing various potential BMDC-mobilizing factors. We therefore tested two different doses of NGR-TNF, a low and a high dose. The rationale for this point is based on the results of several phase I and II clinical trials with NGR-hTNF showing that low doses of the drug, for example, $0.8 \mu \mathrm{g} \mathrm{m}^{-2}$ (Gregorc et al, 2010a) (i.e., $18 \mathrm{ng}$ per $\mathrm{kg}$ ), are more efficacious than higher doses tested in phase I dose escalation studies (van Laarhoven et al, 2010; Gregorc et al, 2010a; Zucali et al, 2013). We reasoned that this counterintuitive result might be explained, at least in part, by the failure of the lower dose to induce a reactive host BMDC response in contrast to the higher dose.

We report that NGR-mTNF, repetitively administered at low doses to tumour-bearing mice, causes a decrease of tumour blood vessel density and induces apoptosis of both tumour and endothelial cells in vivo without inducing a reactive proangiogenic host response.

\section{MATERIALS AND METHODS}

Tumour cells and animal models. Mouse Lewis lung carcinoma (LLC; ATCC, Manassas, VA, USA) and 4T1 mammary gland carcinoma cells (ATCC) were cultured in standard conditions. LLC cells $\left(5 \times 10^{5}\right)$ were subcutaneously (s.c.) injected into syngeneic C57BL/6 mice (Jackson) or C57BL/6 mice previously transplanted with green fluorescent protein ${ }^{+}\left(\mathrm{GFP}^{+}\right)$bone marrow cells from UBI-GFP/BL6 donors (Jackson, Bar Harbor, ME, USA) after lethal irradiation $(900 \mathrm{rad})$. $4 \mathrm{~T} 1$ cells $\left(7 \times 10^{3}\right)$ were s.c. injected into syngeneic BALB/c mice (Charles River, Calco, Lecco, Italy). Treatments started when tumours were $200-300 \mathrm{~mm}^{3}$. Mice were sacrificed when tumour sizes reached $1700 \mathrm{~mm}^{3}$, with the approval and in accordance with the guidelines of the animal care committee of the Sunnybrook Health Sciences Centre and Canadian Council of Animal Care and the Ethical Committee of the San Raffaele Scientific Institute (IACUC 492). Our in vivo experiments meet the standards required by the UKCCCR guidelines (Workman et al, 2010).

Preparation and characterisation of NGR-mTNF. The cDNA coding for NGR-mTNF was kindly provided by Dr A Corti (San Raffaele Scientific Institute, Milan, Italy). NGR-mTNF expression was induced in transformed BL21 (2D3) Escherichia Coli (Novagen, Podenzano, PC, Italy) by $1 \mathrm{~mm}$ IPTG (Sigma-Aldrich, St Louis, MO, USA). Bacterial homogenate was clarified by flocculation with polyethyleneimine (Sigma-Aldrich), and soluble NGR-mTNF was purified by three stage of chromatography: ion-exchange chromatography on Q-Sepharose XL (GE Healthcare, Milan, Italy), mixed-mode chromatography on Capto Adhere (GE Healthcare) and ion-exchange chromatography on Q-Sepharose HP (GE Healthcare) in denaturing conditions. The endotoxin content of the purified NGR-mTNF, measured by the quantitative chromogenic Limulus amebocyte lysate test (BioWhittaker, Lonza,

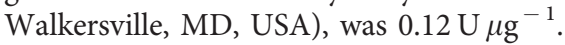

Tumour treatments. NGR-mTNF was administered intraperitoneally (i.p.) either at high dose $\left(1\right.$ or $10 \mu \mathrm{g} 100 \mu \mathrm{l}^{-1}$ per mouse, used indifferently because they gave the same results as far as 
BMDCs and growth factor release and efficacy are concerned), single-bolus injections, or at low dose ( $0.1 \mathrm{ng} 100 \mu \mathrm{l}^{-1}$ per mouse), three times a week. A rat monoclonal antibody specific for mouse VEGFR-2/flk-1 (DC101) was administered i.p. at a concentration of $800 \mu \mathrm{g} 200 \mu \mathrm{l}^{-1}$ per mouse. A second-generation vascular microtubule-disrupting agent, Oxi4503 (designated from now on as 'VDA'), was administered i.p. at $100 \mu \mathrm{gg}^{-1}$ as a single dose.

Bone marrow transplantation. Green fluorescent protein ${ }^{+}$bone marrow cells $\left(10 \times 10^{6}\right)$ isolated from femurs of UBI-GFP/BL6 donor mice were injected into the tail veins of 6- to 8-week-old lethally irradiated (900 rad) C57BL/6 female mice. After 6-8 weeks, recipient mice were bled from the orbital sinus to evaluate bone marrow transplantation efficiency using flow cytometry. Those that had $>99 \% \mathrm{GFP}^{+}$peripheral blood cells were subsequently used as recipients for a subcutaneous injection of LLC cells.

Analysis of circulating cells by flow cytometry. Blood was drawn from the retro-orbital sinus of anaesthetised mice 4,24 and $72 \mathrm{~h}$ after a single treatment or 24 or $72 \mathrm{~h}$ after repeated (three) treatments with NGR-mTNF. Cell suspensions were analysed on an LSRII or a FACSCanto (BD Biosciences, San Diego, CA, USA) after red cell lysis. At least 100000 cells per sample were acquired, and percentages of stained cells were determined and compared with appropriate negative controls. Viable CECs (vCECs) and viable CEPs (vCEPs) were counted using five-colour flow cytometry. Briefly, monoclonal antibodies specific for CD45 were used to exclude CD45 haematopoietic cells, and CECs or CEPs were detected as expressing the murine endothelial markers fetal liver kinase 1/VEGF receptor 2 (flk-1/VEGFR-2), CD13 and (only) for CEPs, CD117 (c-kit) (BD Biosciences). After acquisition of at least 100000 cells per sample, analyses were considered informative when an adequate number of events (i.e., $>25$, typically 50-150) were collected in the CEP enumeration gate in untreated control animals (Bertolini et al, 2006). Positive staining was defined as being greater than nonspecific background staining, and 7-aminoactinomycin D (7AAD) was used to distinguish apoptotic and dead cells from viable cells (Bertolini

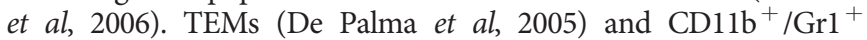
MDSCs were detected as being positive for CD45, CD11b (BD Biosciences), Tie2 (eBioscience, San Diego, CA, USA) and CD45, CD11b, Gr1 (Ly6G, BD Biosciences) markers, respectively.

Evaluation of circulating growth factor plasma levels by ELISA. Mice were treated when tumours were $250-350 \mathrm{~mm}^{3}$. Blood was drawn from the retro-orbital sinuses of anaesthetised mice or by cardiac puncture 4,24 or $72 \mathrm{~h}$ after treatment with either NGR-mTNF or VDA. Plasma samples were obtained by centrifugation (3000 revolutions per $\min$ (r.p.m.), $5 \mathrm{~min}$ ) and stored at $-80^{\circ} \mathrm{C}$. Levels of G-CSF, SDF-1 and OPN were assessed with commercially available DuoSet R\&D System ELISA assays following the manufacturer's instructions. Standard curve for G-CSF started from $1000 \mathrm{pg} \mathrm{ml}^{-1}$ and samples were diluted $1: 2$; a standard curve for SDF-1 started from $1000 \mathrm{pg} \mathrm{ml}^{-1}$ and samples were diluted $1: 1$; and a standard curve for OPN started from $2 \mathrm{ng} \mathrm{ml}^{-1}$ and samples were diluted $1: 450$.

Tumour immunofluorescence and immunohistochemistry. Tumour tissues were collected $72 \mathrm{~h}$ after a single treatment or $24 \mathrm{~h}$ after repeated (three) treatments, snap frozen and stored at $-80{ }^{\circ} \mathrm{C}$. Tumour cryosections $(15-20 \mu \mathrm{m})$ were stained for vessels with an anti-CD31 antibody (1:200, BD Biosciences) and its secondary Dylight649-conjugated donkey anti-rat antibody (1:200, Jackson ImmunoResearch, West Grove, PA, USA) or Cy3-conjugated donkey anti-rat antibody (1:200, Jackson ImmunoResearch), for apoptosis with an anticleaved caspase- 3 antibody (Cell Signaling Technology, Boston, MA, USA) and its secondary Cy3-conjugated donkey anti-rabbit antibody $(1: 200$, Jackson ImmunoResearch) and for GFP positivity with an antiGFP fluorescein isothiocyanate (FITC)-conjugated antibody
(1:500, BD Biosciences). All sections were counterstained with DAPI for identifying nuclei. Controls were immunostained with a secondary antibody alone. For detecting hypoxia, mice received an i.p. injection of pimonidazole hydrochloride $(60 \mathrm{mg}$ per $\mathrm{kg}$ ) (Chemicon International, Temecula, CA, USA) $90 \mathrm{~min}$ before euthanasia (Daenen et al, 2009). Tumours were then removed, snap frozen and stored at $-80{ }^{\circ} \mathrm{C}$. Hypoxia immunostaining was carried out using the anti-pimonidazole antibody Hypoxyprobe- 1 $(1: 200$, Chemicon International) and its secondary Cy3-conjugated rat anti-mouse antibody ( $1: 200$, Jackson ImmunoResearch). Necrosis was detected as autofluorescence in the FITC channel on sections $(5 \mu \mathrm{m})$ obtained from formalin-fixed, paraffin-embedded tumours (Daenen et al, 2009). Proliferation was determined by immunostaining with a rabbit polyclonal Ki-67 antibody (Vector, Burlington, ON, Canada) on sections $(5 \mu \mathrm{m})$ obtained from formalin-fixed, paraffin-embedded tumours. Histological data were collected in a blind manner. Images were captured with a Zeiss Axiocam digital camera connected to the microscope using AxioVision 3.0 software. At least two non-consecutive slides were analysed per tumour, and at least 10 pictures (magnification $\times 100$ ) were taken for each slide to represent the whole tumour section. Pictures were analysed with ImageJ and Prism. For each colour (green, red, blue and cyan), the number of pixels per image was divided by the total number of pixels of the tumour area. Results were expressed as fold increase/decrease in comparison with control group (100\%). All the experiments were repeated at least twice. Pictures shown are representative of the most frequently seen fields per slide.

Statistical analysis. GraphPad Prism version 5.0b was used to assess the statistical significance of differences in mean values. The two-tailed Student's $t$-test or the one-way Anova test was used to assess the significance of the mean difference. Difference between designated groups compared with saline-treated group (unless indicated otherwise) was considered significant at values of $0.05>P>0.01\left(^{*}\right)$ or $0.01>P>0.001{ }^{(*)}$ or $P<0.001\left(^{* * *}\right)$. The absence of symbols means that no statistically significant differences were detected. Data are expressed as mean \pm s.d.

\section{RESULTS}

Low-dose NGR-TNF causes a decrease in tumour blood vessel counts and induces apoptosis. Antitumour activity of NGRmTNF has been reported in different tumour models following the administration of low doses of NGR-mTNF alone or in combination with chemotherapeutic agents (Curnis et al, 2000, 2002b; Sacchi et al, 2006; Calcinotto et al, 2012). To assess whether the tumour inhibitory activity of NGR-TNF may involve a local effect on tumour vessels, LLC-bearing mice were treated with either high- or low-dose NGR-mTNF ( $n=4-6$ mice per group). Tumour tissues were collected $72 \mathrm{~h}$ after a single treatment or $24 \mathrm{~h}$ after repeated treatments and stained for CD31 and cleaved caspase-3 (ClCasp3) as a marker of apoptosis. The low-dose treatment and, to a greater extent, the high-dose treatment caused a decrease in tumour-associated blood vessel density $72 \mathrm{~h}$ after treatment (Figures 1A and B). Similar results were obtained on tumours collected after repeated low-dose drug administration (Supplementary Figures 1A and B). As expected, increased levels of ClCasp3 expression were detected in both high-dose- and lowdose-treated tumours (Figure 1C). Indeed, we observed similar levels of apoptosis of both tumour cells and tumour endothelial cells, thus suggesting that even at low doses NGR-TNF has antivascular effects, which could contribute to its antitumour therapeutic activity. This biological activity of NGR-mTNF is translated into a reduction of tumour growth (Supplementary Figure 2A). 


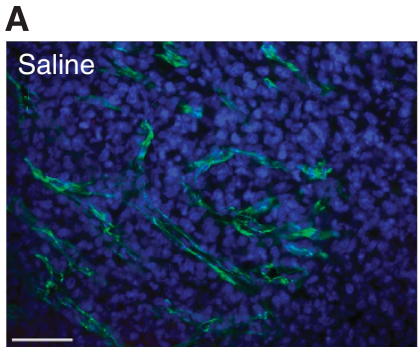

B

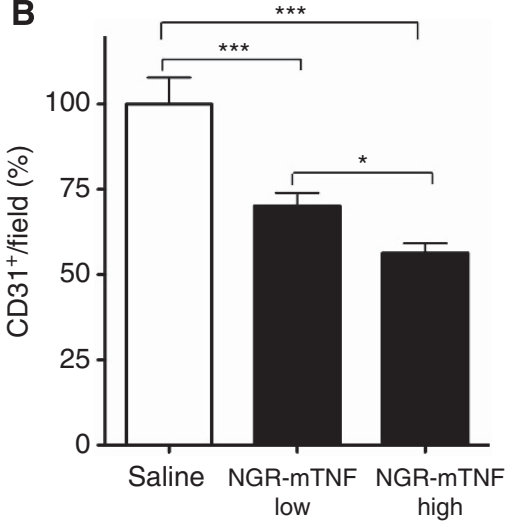

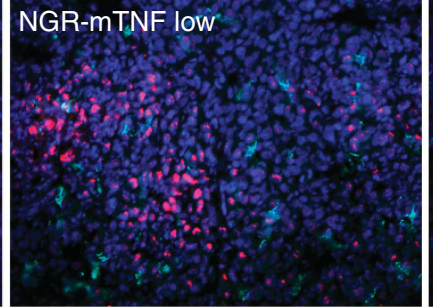
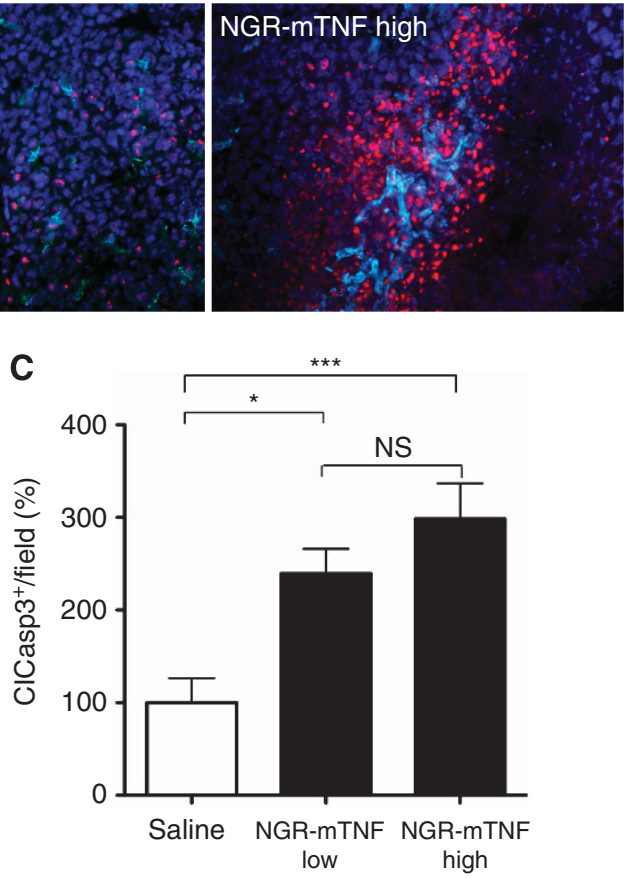

Figure 1. Low-dose NGR-mTNF decreases vascular density and induces apoptosis of tumour cells and tumour endothelial cells. LLC tumours were harvested $72 \mathrm{~h}$ after a single treatment and processed as described in the Materials and Methods section. (A) Cleaved caspase-3 (ClCasp3; red) and CD31 (cyan) immunostaining of LLC tumour sections. Nuclei were stained with DAPI (blue). Results are representative of three independent experiments, and 4-6 mice per group were analysed. For each tumour, 2-10 non-consecutive sections were analysed. At least 10 pictures per slide were taken. Magnification $\times 100$; scale bar, $200 \mu \mathrm{m}$. (B and $\mathbf{C}$ ) The plots show mean ratio of CD31 and CICasp3 expression analysed as the measure of vascular density and apoptosis, respectively.

In particular, $72 \mathrm{~h}$ after treatment, VDA and high-dose NGR-mTNF exert antitumour effects. However, at sacrifice (usually around day 22 after tumour injection, 12 days after the first treatment) the most potent antitumour agent we tested is low-dose NGR-mTNF (Supplementary Figure 2A).

Low-dose NGR-TNF does not induce the mobilisation of proangiogenic BMDCs and proangiogenic growth factors. As VDA treatment has been shown to provoke the induction of multiple host cytokines such as G-CSF (Shaked et al, 2009) or SDF-1 (Welford et al, 2011), which can then act to mobilise several types of BMDC populations, we investigated whether NGR-TNF can induce cytokine-driven recruitment of proangiogenic BMDCs. We analysed blood from LLC-bearing mice obtained in an early phase (4 and $24 \mathrm{~h}$ ) (Shaked et al, 2006) or in a late phase (72 h) (Taylor et al, 2012) after a single treatment or 24 or $72 \mathrm{~h}$ after repeated (three) treatments with either NGR-mTNF or VDA or an antiVEGFR2/flk-1 antibody ( $n=5-6$ mice per group) for the presence of circulating BMDCs by FACS. In particular, vCECs were defined as $\mathrm{CD}_{4} 5^{-} / \mathrm{CD} 13^{+} / \mathrm{flk}^{-1}{ }^{+} / 7 \mathrm{AAD}^{-}$, vCEPs as $\mathrm{CD} 45^{-} / \mathrm{CD} 13^{+} /$ flk- $1^{+} / \mathrm{CD} 117^{+} / 7 \mathrm{AAD}^{-}$, TEMs as $\mathrm{CD} 45^{+} / \mathrm{CD} 11 \mathrm{~b}^{+} / \mathrm{Tie} 2^{+}$and MDSCs as $\mathrm{CD} 45^{+} / \mathrm{CD} 11 \mathrm{~b}^{+} / \mathrm{Gr} 1^{+}$cells. VDA treatment induced the mobilisation of vCEPs, vCECs, TEMs and $\mathrm{CD} 11 \mathrm{~b}^{+} \mathrm{Gr}^{+}$cells (Figure 2A). Furthermore, we observed increased levels of circulating proangiogenic BMDCs after treatment with high doses of NGR-mTNF (Figure 2A), whereas both single (Figure 2A) and repeated (Supplementary Figure 3 ) treatments with NGR-mTNF at low dose did not induce such cell mobilisation. Indeed, in the latter setting, increased levels of circulating $\mathrm{CD} 45^{+} / \mathrm{CD} 11 \mathrm{~b}^{+} / \mathrm{Gr} 1^{+}$cells were observed after repeated administration of both saline and NGR-mTNF at low dose probably because of the inflammation and the stress associated to the manipulations (Everds, 2007). The results obtained were confirmed in the $4 \mathrm{~T} 1$ model, where increases in circulating proangiogenic BMDCs were observed after high-dose treatments but not after low-dose NGR-mTNF treatments (Figure 3). To in deep characterise the phenomenon, we also looked for circulating proangiogenic BMDCs after treatment with intermediate doses of NGR-mTNF, 1 and $10 \mathrm{ng}$ per mouse (Supplementary Figure 4). At $10 \mathrm{ng}$ per mouse, we observed the release of proangiogenic BMDCs into circulation, thus suggesting that this phenomenon is already active in the nanogram range (Supplementary Figure 4).

Next, we assessed the presence of circulating factors, previously shown to be involved in mobilisation of CEPs and some other BMDC types such as TEMs (e.g., G-CSF, SDF-1 and OPN) by ELISAs. VDA treatment, as well as high-dose NGR-mTNF, induced a significant increase of the plasma level of G-CSF, OPN and SDF-1, which was not detected either 4 or $24 \mathrm{~h}$ after treatment with NGR-mTNF at low dose (Figure 2B). The increase of growth factors is transient as $72 \mathrm{~h}$ after treatment all the growth factors tested returned to basal levels (data not shown). These results suggested that low-dose NGR-mTNF, comparable to the doses being used in the ongoing clinical trials (mouse: about $6 \mathrm{ng}$ per $\mathrm{kg}$; human: $0.8 \mu \mathrm{g} \mathrm{m}^{-2}$ corresponding to about $18 \mathrm{ng}$ per $\mathrm{kg}$ ) (Gregorc et al, 2010a), does not cause a rebound of the potentially proangiogenic circulating growth factors that we assessed, nor the associated mobilisation of proangiogenic BMDCs.

Low-dose NGR-TNF does not recruit BMDCs to the tumour site. To investigate the presence of potential tumour growthpromoting proangiogenic BMDCs at the tumour site, we treated LLC-bearing $\mathrm{GFP}^{+}$bone marrow chimaeric mice with either NGR-TNF or VDA or an anti-VEGFR2/flk-1 antibody $(n=4-6$ mice per group). Tumour tissues were collected $72 \mathrm{~h}$ after treatment and analysed for the presence of $\mathrm{GFP}^{+}$BMDCs (Figure 4A). GFP ${ }^{+}$cells were observed in all the groups at variable levels, with a statistically significant increase detectable only in the VDA-treated tumours (Figures $4 \mathrm{~A}$ and B). In line with 

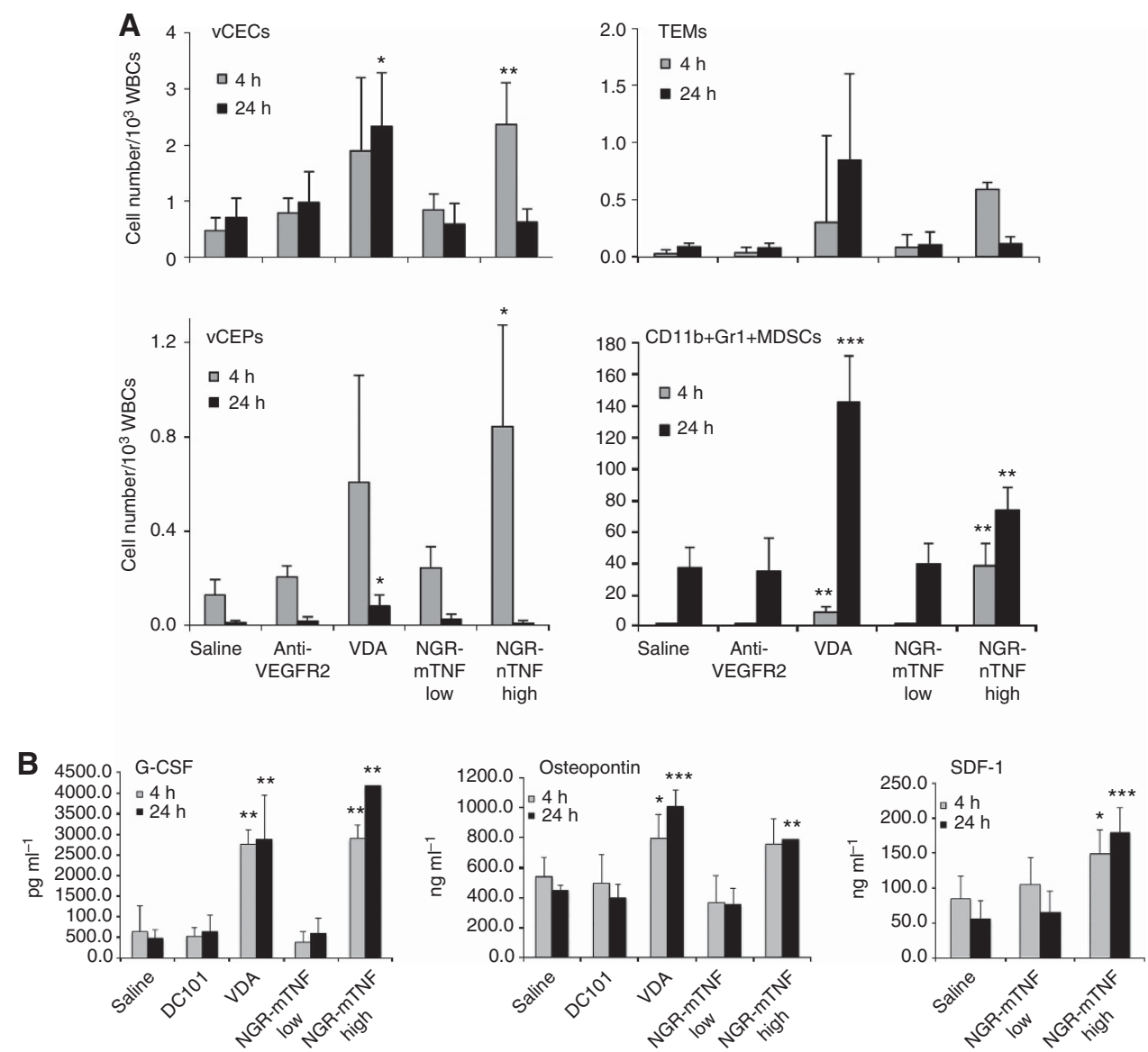

Figure 2. Low-dose NGR-mTNF does not modify the levels of circulating potentially tumour-promoting BMDCs and circulating GFs.

(A) Levels of circulating vCECs, vCEPs, TEMs and CD11 b ${ }^{+} \mathrm{Gr} 1^{+}$MDSCs in LLC tumour-bearing mice $(n=5)$ were evaluated by FACS analysis 4 and $24 \mathrm{~h}$ after treatment with the indicated drugs. (B) Plasma levels of G-CSF, OPN and SDF-1 were obtained from LLC tumour-bearing mice $(n=5) 4$ and $24 \mathrm{~h}$ after treatment with the indicated drugs.
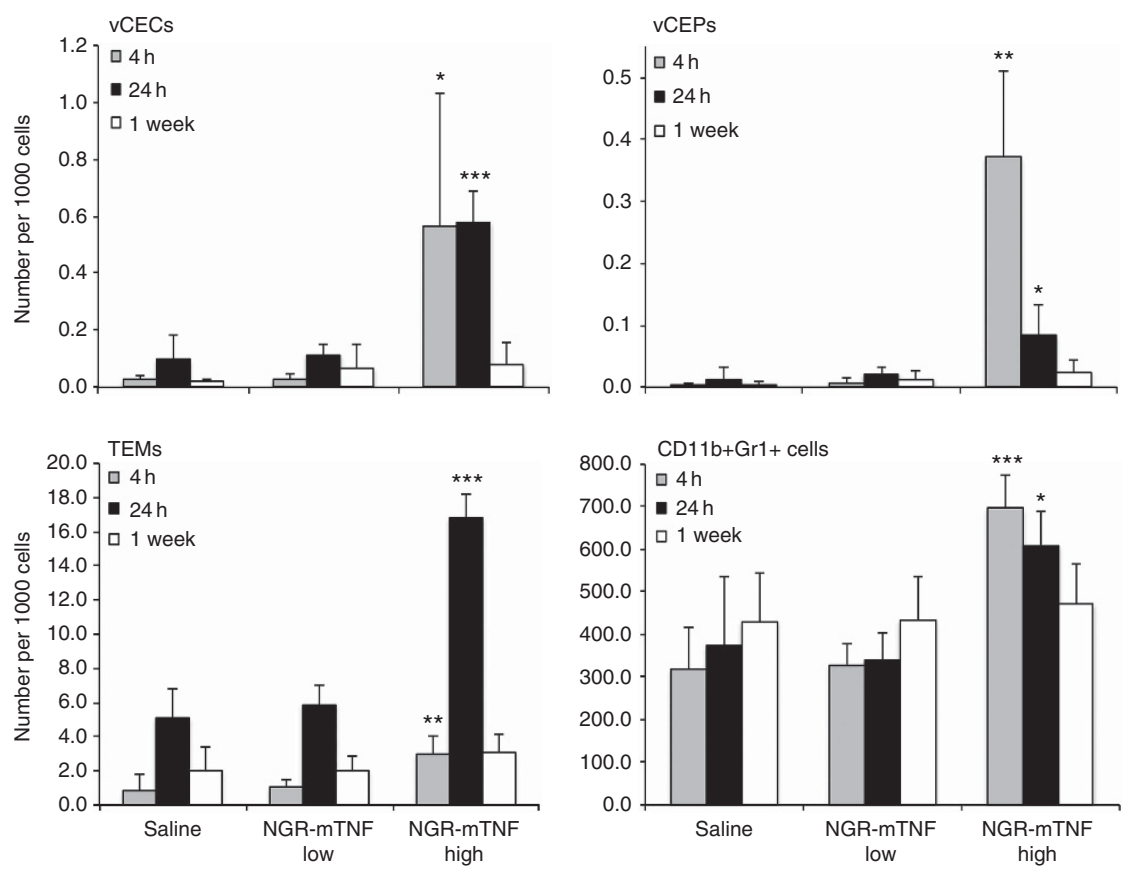

Figure 3. NGR-mTNF does not increase the levels of circulating tumour-promoting BMDCs in a mouse model of breast cancer. Levels of circulating vCEPs, vCECs, TEMs and CD11 $\mathrm{b}^{+} \mathrm{Gr} 1^{+}$MDSCs in 4T1 tumour-bearing mice $(n=5)$ were evaluated by FACS analysis 4 or $24 \mathrm{~h}$ or 1 week after the first treatment with the indicated drugs. 

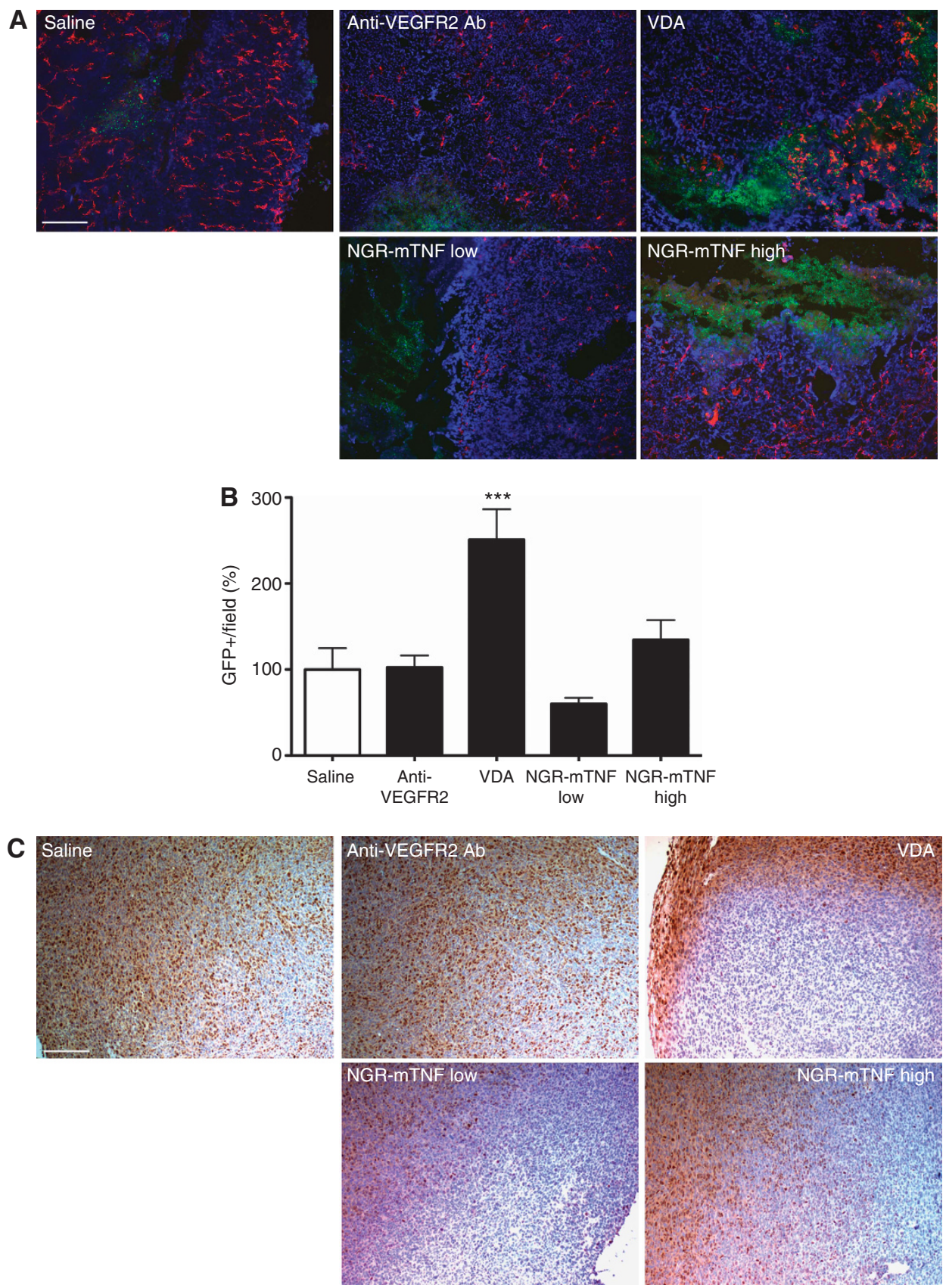

Figure 4. Low-dose NGR-mTNF does not support the BMDC-induced viable and proliferating tumour rim. LLC tumours grown in GFP ${ }^{+}$bone marrow chimaeric mice were harvested $72 \mathrm{~h}$ after a single treatment and processed as described in the Materials and Methods section. (A) GFP ${ }^{+}$ BM-derived cells (green) and CD31 (red) immunostaining of LLC tumour sections. Nuclei were stained with DAPI (blue). Results are representative of two independent experiments, and 4-6 mice per group were analysed. For each tumour, 2-10 non-consecutive sections were analysed. At least 10 pictures per slide were taken. Magnification $\times 100$; scale bar, $200 \mu \mathrm{m}$. (B) The plot illustrates quantification of tumour-infiltrating GFP ${ }^{+}$ cells. The plot shows mean ratio of GFP staining analysed. (C) Ki67 (brown) immunostaining of paraffin-embedded LLC tumour sections. Nuclei were stained with haematoxylin (blue). Results are representative of two independent experiments, and 4-6 mice per group were analysed. For each tumour, 2-10 non-consecutive sections were analysed. At least 10 pictures per slide were taken. Magnification $\times 100$; scale bar, $200 \mu \mathrm{m}$.

the rapid tumour regrowth previously described to occur after VDA therapy, we observed $\mathrm{GFP}^{+} \mathrm{BMDC}$ localisation at the viable tumour rim in VDA-treated tumours and to a lesser extent in the high-dose NGR-mTNF-treated tumours. Significantly, no viable tumour rim was observed after administration of low-dose NGR-mTNF.

To further investigate the effects of the treatments on tumour cell proliferation, we analysed LLC tumours recovered $72 \mathrm{~h}$ after treatment for Ki67 staining. In agreement with the localisation of $\mathrm{GPF}^{+} \mathrm{BMDCs}$ at the viable tumour rim, tumour cell proliferation was clearly observed at the edge of VDA- and high-dose NGR-mTNF-treated tumours, further supporting the presence of a viable regrowing (repopulating) tumour rim (Figure 4C). In contrast, treatment with low-dose NGR-mTNF modestly reduced tumour cell proliferation and, more importantly, did not lead to the formation of highly proliferative viable tumour rims (Figure 4C), thus avoiding or minimizing rapid tumour regrowth.

Low-dose NGR-TNF induces low-grade hypoxia and necrosis. Several factors may contribute to VDA-mediated mobilisation 
of BMDCs, including host-mediated, tumour-independent effects that may be related to direct toxicity of the drugs on bone marrow cells, as well as the elevated levels of tumour hypoxia and tumour cell necrosis induced by drug treatment (Bergers and Hanahan, 2008; Du et al, 2008). To further investigate the mechanism of action of low-dose NGR-mTNF, we evaluated its ability to induce tumour hypoxia and necrosis in LLC tumours, using pimonidazole staining as a marker of hypoxia and autofluorescence as a marker of necrosis (Daenen et al, 2009). As expected, treatments with VDA or high-dose NGR-mTNF increased tumour hypoxia and necrosis (Figures $5 \mathrm{~A}-\mathrm{C}$ ). Low-dose NGR-mTNF only slightly increased these two parameters
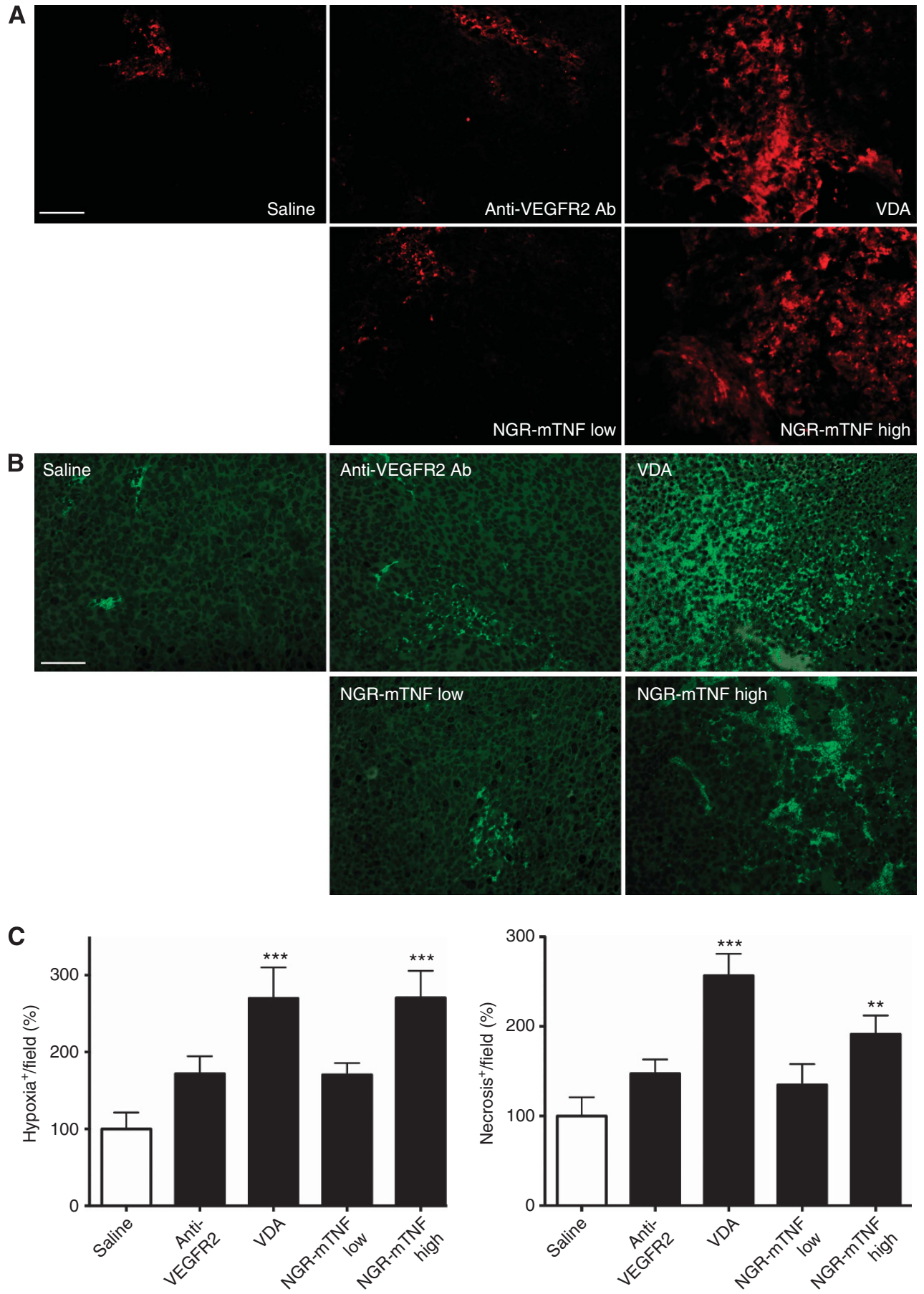

Figure 5. Low-dose NGR-mTNF effects on tumour hypoxia and necrosis. LLC tumours were harvested $72 \mathrm{~h}$ after a single treatment and processed as described in the Materials and Methods section. (A) The level of hypoxia was evaluated as pimonidazole (red) immunostaining. Results are representative of two independent experiments, and 4-6 mice per group were analysed. For each tumour, 2-10 non-consecutive sections were analysed. At least 10 pictures per slide were taken. Magnification $\times 100$; scale bar, $200 \mu \mathrm{m}$. (B) The level of necrosis was evaluated as autofluorescence (green) of paraffin-embedded sections. Results are representative of two independent experiments, and 4-6 mice per group were analysed. For each tumour, 2-20 non-consecutive sections were analysed. At least 10 pictures per slide were taken. Magnification $\times 100$; scale bar, $200 \mu \mathrm{m}$. (C) Left panel illustrates quantification of tumour hypoxia. The plot shows mean ratio of pimonidazole immunostaining analysed; right panel illustrates quantification of tumour necrosis. The plot shows the mean ratio of green pixels/field analysed. 
(Figures $5 \mathrm{~A}-\mathrm{C}$ ), in agreement with the observation that low-dose NGR-TNF treatment fails to induce robust cytokine/growth factor or BMDC responses.

\section{DISCUSSION}

Various angiogenesis inhibitors targeting the VEGF pathway have demonstrated proven efficacy in both preclinical tumour models and in clinical trials. However, in both settings the therapeutic effects are transient, and after an initial phase of tumour growth control, for example, tumour regression in some cases, or induction of stable disease, the tumours progress. As such, there is considerable interest in elucidating the reasons for their transient clinical benefits, for example, understanding the basis of intrinsic or acquired resistance mechanisms, and devising strategies to delay the onset of resistance or treat overt recurrent resistant disease with second-line therapies-including with new and different antiangiogenic drugs or other types of vascular-targeting agents/ strategies such as VDAs (Bergers and Hanahan, 2008; Ebos and Kerbel, 2011). In this context, the recruitment of BM-derived proangiogenic cells at the tumour site has been identified as one possible reason of the transient efficacy of some of these treatments, such as VDAs, in preclinical models (Shaked et al, 2006, 2008; Welford et al, 2011). Moreover, the relevance of this mechanism in patients treated with VDAs is supported by several clinical studies (Farace et al, 2007; Shaked et al, 2009; Taylor et al, 2012).

The combination properties of NGR-TNF define a new class of vascular-targeting agent. For example, unlike both antiangiogenic VEGF pathway-targeting drugs and VDAs, NGR-TNF neither induces hypertension nor causes proteinuria. Like VDAs, it can directly attack the tumour vasculature, but the molecular target for NGR-TNF expressed by endothelial cells - CD13 - is known. Unlike VDAs or antiangiogenic VEGF pathway inhibitors, it has an additional mechanism of action, namely, potent stimulation of host antitumour immune mechanisms (Curnis et al, 2000; Sacchi et al, 2004; Balza et al, 2006; Calcinotto et al, 2012). In addition, NGR-TNF therapy has been shown to rapidly increase the intratumour uptake of chemotherapy drugs such as doxorubicin as a consequence of the damage inflicted upon the integrity of the tumour vasculature resulting in increased vascular permeability (Sacchi et al, 2006; Gregorc et al, 2009).

One of the properties of conventionally dosed direct vasculartargeting VDAs, which has been preclinically shown to limit its otherwise potent initial antitumour efficacy, is its effect on inducing a rapid systemic mobilisation of BMDCs including CEPs and/or TEMs that then home to and colonise the drug-treated tumours (Shaked et al, 2006; Welford et al, 2011; Taylor et al, 2012). The CEP host response can be partially blocked by cotreatment with VEGF- or VEGF receptor-2-neutralizing antibodies, which results in improved antitumour effects mediated by the VDA (Shaked et al, 2006). Based on these observations, mimicking the doses used in the clinical setting, we investigated whether NGR-TNF, compared with other vascular-targeting agents, causes an increase of circulating host-derived cytokines or growth factors and mobilises/recruits BMDCs to the tumour site. We tested two different doses of NGR-TNF, a low and a high dose. Clinical trials showed that low doses of NGR-hTNF, for example, $0.8 \mu \mathrm{g} \mathrm{m}^{-2}$ (i.e., $18 \mathrm{ng}$ per $\mathrm{kg}$ ), are more efficacious than higher doses (Gregorc et al, 2010a; Zucali et al, 2013). Our results indeed indicate that the low dose of NGR-TNF neither induces the robust mobilisation of several types of BMDCs, including CEPs, TEMs and MDSCs, nor increases the levels of G-CSF, SDF-1 and OPN. In contrast, treatments with high-dose NGR-TNF resulted in BMDC mobilisation and in increased levels of growth factors.
These responses are similar in nature to those observed with conventionally dosed VDAs or certain chemotherapy drugs administered at maximum tolerated doses (Bertolini et al, 2003; Shaked et al, 2006, 2008; Welford et al, 2011).

Whether lower doses of VDAs administered in a metronomic scheduling manner would also avoid induction of BMDC responses and would show similar or even increased antitumour efficacy is presently unknown, and is worth investigating. Another open question, deserving deeper investigation in suitable tumour models, is the effects that NGR-TNF treatment may have on the metastatic process, which it is known to be enhanced by BMDC mobilisation (Gingis-Velitski et al, 2011).

We observed that, as already reported by others (Shaked et al, 2006; Taylor et al, 2012), mice treated with VDA showed a significant increase of tumour-infiltrating $\mathrm{GFP}^{+}$BMDCs compared with that in the saline-treated mice. Similar results, even if not statistically significant, were also observed in the high-dose NGR-TNF group, thus suggesting a correlation between the raise of CEPs, TEMs and MDSCs detected in peripheral blood and the level of $\mathrm{GFP}^{+}$BMDCs observed in tumours. In agreement, mice administered with low-dose NGR-TNF and anti-VEGFR2, agents that do not mobilise proangiogenic BMDCs, showed mild incorporation of $\mathrm{GFP}^{+}$BMDCs in LLC tumours, comparable with that observed in saline-treated mice.

Our results add to a growing body of evidence showing the potential benefits of using cytotoxic drugs, including chemotherapy, in more metronomic-like scheduling and dosing protocols. In addition, the properties and mechanisms of action of NGR-TNF suggest that it would be a particularly promising drug to consider not only for front-line therapy in combination with chemotherapy but also as a second-line therapy when resistance to antiangiogenic drugs such as bevacizumab or small molecular TKIs has developed. In such situations, the use of a direct-acting molecular vasculartargeting agent could be particularly effective because its action does not depend on VEGF or VEGF receptors as a target and also because it exploits additional antitumour mechanisms, such as stimulation of host immunity. In summary, our results provide a rationale for using repetitive low-dose NGR-TNF administration schedules in the clinic, in addition to the expected reduced toxicities that would ensue for such protocols.

\section{ACKNOWLEDGEMENTS}

We thank Cassandra Cheng for her excellent secretarial assistance. RSK holds a Canada Research Chair in Tumour Biology, Angiogenesis and Antiangiogenic Therapy.

\section{REFERENCES}

Arap W, Pasqualini R, Ruoslahti E (1998) Cancer treatment by targeted drug delivery to tumor vasculature in a mouse model. Science 279(5349): 377-380.

Balza E, Mortara L, Sassi F, Monteghirfo S, Carnemolla B, Castellani P, Neri D, Accolla RS, Zardi L, Borsi L (2006) Targeted delivery of tumor necrosis factor-alpha to tumor vessels induces a therapeutic T cellmediated immune response that protects the host against syngeneic tumors of different histologic origin. Clin Cancer Res 12(8): 2575-2582.

Bergers G, Hanahan D (2008) Modes of resistance to anti-angiogenic therapy. Nat Rev Cancer 8(8): 592-603.

Bertolini F, Paul S, Mancuso P, Monestiroli S, Gobbi A, Shaked Y, Kerbel RS (2003) Maximum tolerable dose and low-dose metronomic chemotherapy have opposite effects on the mobilization and viability of circulating endothelial progenitor cells. Cancer Res 63(15): 4342-4346.

Bertolini F, Shaked Y, Mancuso P, Kerbel RS (2006) The multifaceted circulating endothelial cell in cancer: towards marker and target identification. Nat Rev Cancer 6(11): 835-845. 
Buehler A, van Zandvoort MA, Stelt BJ, Hackeng TM, Schrans-Stassen BH, Bennaghmouch A, Hofstra L, Cleutjens JP, Duijvestijn A, Smeets MB, de Kleijn DP, Post MJ, de Muinck ED (2006) cNGR: a novel homing sequence for CD13/APN targeted molecular imaging of murine cardiac angiogenesis in vivo. Arterioscler Thromb Vasc Biol 26(12): 2681-2687.

Calcinotto A, Grioni M, Jachetti E, Curnis F, Mondino A, Parmiani G, Corti A, Bellone M (2012) Targeting TNF-alpha to neoangiogenic vessels enhances lymphocyte infiltration in tumors and increases the therapeutic potential of immunotherapy. J Immunol 188(6): 2687-2694.

Conejo-Garcia JR, Benencia F, Courreges MC, Kang E, Mohamed-Hadley A, Buckanovich RJ, Holtz DO, Jenkins A, Na H, Zhang L, Wagner DS,

Katsaros D, Caroll R, Coukos G (2004) Tumor-infiltrating dendritic cell precursors recruited by a beta-defensin contribute to vasculogenesis under the influence of Vegf-A. Nat Med 10(9): 950-958.

Coussens LM, Raymond WW, Bergers G, Laig-Webster M, Behrendtsen O, Werb Z, Caughey GH, Hanahan D (1999) Inflammatory mast cells upregulate angiogenesis during squamous epithelial carcinogenesis. Genes Dev 13(11): 1382-1397.

Curnis F, Arrigoni G, Sacchi A, Fischetti L, Arap W, Pasqualini R, Corti A (2002a) Differential binding of drugs containing the NGR motif to CD13 isoforms in tumor vessels, epithelia, and myeloid cells. Cancer Res 62(3): 867-874.

Curnis F, Sacchi A, Borgna L, Magni F, Gasparri A, Corti A (2000) Enhancement of tumor necrosis factor alpha antitumor immunotherapeutic properties by targeted delivery to aminopeptidase $\mathrm{N}$ (CD13). Nat Biotechnol 18(11): 1185-1190.

Curnis F, Sacchi A, Corti A (2002b) Improving chemotherapeutic drug penetration in tumors by vascular targeting and barrier alteration. J Clin Invest 110(4): 475-482.

Daenen LG, Shaked Y, Man S, Xu P, Voest EE, Hoffman RM, Chaplin DJ, Kerbel RS (2009) Low-dose metronomic cyclophosphamide combined with vascular disrupting therapy induces potent antitumor activity in preclinical human tumor xenograft models. Mol Cancer Ther 8(10): 2872-2881

De Palma M, Lewis CE (2011) Cancer: macrophages limit chemotherapy Nature 472(7343): 303-304.

De Palma M, Venneri MA, Galli R, Sergi Sergi L, Politi LS, Sampaolesi M, Naldini L (2005) Tie2 identifies a hematopoietic lineage of proangiogenic monocytes required for tumor vessel formation and a mesenchymal population of pericyte progenitors. Cancer Cell 8(3): 211-226.

De Palma M, Venneri MA, Roca C, Naldini L (2003) Targeting exogenous genes to tumor angiogenesis by transplantation of genetically modified hematopoietic stem cells. Nat Med 9(6): 789-795.

Denardo DG, Brennan DJ, Rexhepaj E, Ruffell B, Shiao SL, Madden SF, Gallagher WM, Wadhwani N, Keil SD, Junaid SA, Rugo HS, Hwang ES, Jirstrom K, West BL, Coussens LM (2011) Leukocyte complexity predicts breast cancer survival and functionally regulates response to chemotherapy. Cancer Discov 1: 54-67.

Du R, Lu KV, Petritsch C, Liu P, Ganss R, Passegue E, Song H, Vandenberg S, Johnson RS, Werb Z, Bergers G (2008) HIF1alpha induces the recruitment of bone marrow-derived vascular modulatory cells to regulate tumor angiogenesis and invasion. Cancer Cell 13(3): 206-220.

Ebos JM, Kerbel RS (2011) Antiangiogenic therapy: impact on invasion, disease progression, and metastasis. Nat Rev Clin Oncol 8(4): 210-221.

Everds NE (2007) Hematology of the laboratory mouse. In: The Mouse in Biomedical Research: Normative Biology, Husbandry, and Models vol. 3, chapter 5, pp 133-170. Elsevier Inc.: Amsterdam.

Farace F, Massard C, Borghi E, Bidart JM, Soria JC (2007) Vascular disrupting therapy-induced mobilization of circulating endothelial progenitor cells. Ann Oncol 18(8): 1421-1422.

Gao D, Nolan DJ, Mellick AS, Bambino K, McDonnell K, Mittal V (2008) Endothelial progenitor cells control the angiogenic switch in mouse lung metastasis. Science 319(5860): 195-198.

Gingis-Velitski S, Loven D, Benayoun L, Munster M, Bril R, Voloshin T, Alishekevitz D, Bertolini F, Shaked Y (2011) Host response to short-term, single-agent chemotherapy induces matrix metalloproteinase- 9 expression and accelerates metastasis in mice. Cancer Res 71(22): 6986-6996.

Gregorc V, Citterio G, Vitali G, Spreafico A, Scifo P, Borri A, Donadoni G, Rossoni G, Corti A, Caligaris-Cappio F, Del Maschio A, Esposito A, De Cobelli F, Dell'Acqua F, Troysi A, Bruzzi P, Lambiase A, Bordignon C (2010a) Defining the optimal biological dose of NGR-hTNF, a selective vascular targeting agent, in advanced solid tumours. Eur J Cancer 46(1): 198-206.
Gregorc V, De Braud FG, De Pas TM, Scalamogna R, Citterio G, Milani A, Boselli S, Catania C, Donadoni G, Rossoni G, Ghio D, Spitaleri G, Ammannati C, Colombi S, Caligaris-Cappio F, Lambiase A, Bordignon C (2011) Phase I study of NGR-hTNF, a selective vascular targeting agent, in combination with cisplatin in refractory solid tumors. Clin Cancer Res 17(7): 1964-1972.

Gregorc V, Santoro A, Bennicelli E, Punt CJ, Citterio G, Timmer-Bonte JN, Caligaris Cappio F, Lambiase A, Bordignon C, van Herpen CM (2009) Phase Ib study of NGR-hTNF, a selective vascular targeting agent, administered at low doses in combination with doxorubicin to patients with advanced solid tumours. Br J Cancer 101(2): 219-224.

Gregorc V, Zucali PA, Santoro A, Ceresoli GL, Citterio G, De Pas TM, Zilembo N, De Vincenzo F, Simonelli M, Rossoni G, Spreafico A, Grazia Vigano M, Fontana F, De Braud FG, Bajetta E, Caligaris-Cappio F, Bruzzi P, Lambiase A, Bordignon C (2010b) Phase II study of asparagine-glycinearginine-human tumor necrosis factor alpha, a selective vascular targeting agent, in previously treated patients with malignant pleural mesothelioma. J Clin Oncol 28(15): 2604-2611.

Kaplan RN, Riba RD, Zacharoulis S, Bramley AH, Vincent L, Costa C, MacDonald DD, Jin DK, Shido K, Kerns SA, Zhu Z, Hicklin D, Wu Y, Port JL, Altorki N, Port ER, Ruggero D, Shmelkov SV, Jensen KK, Rafii S, Lyden D (2005) VEGFR1-positive haematopoietic bone marrow progenitors initiate the pre-metastatic niche. Nature 438(7069): 820-827. Kerbel RS (2008) Tumor angiogenesis. N Engl J Med 358(19): 2039-2049.

Lin EY, Li JF, Gnatovskiy L, Deng Y, Zhu L, Grzesik DA, Qian H, Xue XN, Pollard JW (2006) Macrophages regulate the angiogenic switch in a mouse model of breast cancer. Cancer Res 66(23): 11238-11246.

Lyden D, Hattori K, Dias S, Costa C, Blaikie P, Butros L, Chadburn A, Heissig B, Marks W, Witte L, Wu Y, Hicklin D, Zhu Z, Hackett NR, Crystal RG, Moore MA, Hajjar KA, Manova K, Benezra R, Rafii S (2001) Impaired recruitment of bone-marrow-derived endothelial and hematopoietic precursor cells blocks tumor angiogenesis and growth. Nat Med 7(11): 1194-1201.

Murdoch C, Muthana M, Coffelt SB, Lewis CE (2008) The role of myeloid cells in the promotion of tumour angiogenesis. Nat Rev Cancer 8(8): 618-631.

Nozawa H, Chiu C, Hanahan D (2006) Infiltrating neutrophils mediate the initial angiogenic switch in a mouse model of multistage carcinogenesis. Proc Natl Acad Sci USA 103(33): 12493-12498.

Pasqualini R, Koivunen E, Kain R, Lahdenranta J, Sakamoto M, Stryhn A, Ashmun RA, Shapiro LH, Arap W, Ruoslahti E (2000) Aminopeptidase N is a receptor for tumor-homing peptides and a target for inhibiting angiogenesis. Cancer Res 60(3): 722-727.

Qian BZ, Pollard JW (2010) Macrophage diversity enhances tumor progression and metastasis. Cell 141(1): 39-51.

Sacchi A, Gasparri A, Curnis F, Bellone M, Corti A (2004) Crucial role for interferon gamma in the synergism between tumor vasculature-targeted tumor necrosis factor alpha (NGR-TNF) and doxorubicin. Cancer Res 64(19): 7150-7155.

Sacchi A, Gasparri A, Gallo-Stampino C, Toma S, Curnis F, Corti A (2006) Synergistic antitumor activity of cisplatin, paclitaxel, and gemcitabine with tumor vasculature-targeted tumor necrosis factor-alpha. Clin Cancer Res 12(1): 175-182.

Santoro A, Rimassa L, Sobrero AF, Citterio G, Sclafani F, Carnaghi C, Pessino A, Caprioni F, Andretta V, Tronconi MC, Finocchiaro G, Rossoni G, Zanoni A, Miggiano C, Rizzardi GP, Traversari C, Caligaris-Cappio F, Lambiase A, Bordignon C (2010) Phase II study of NGR-hTNF, a selective vascular targeting agent, in patients with metastatic colorectal cancer after failure of standard therapy. Eur J Cancer 46(15): $2746-2752$

Shaked Y, Ciarrocchi A, Franco M, Lee CR, Man S, Cheung AM, Hicklin DJ, Chaplin D, Foster FS, Benezra R, Kerbel RS (2006) Therapy-induced acute recruitment of circulating endothelial progenitor cells to tumors. Science 313(5794): 1785-1787.

Shaked Y, Henke E, Roodhart JM, Mancuso P, Langenberg MH, Colleoni M, Daenen LG, Man S, Xu P, Emmenegger U, Tang T, Zhu Z, Witte L, Strieter RM, Bertolini F, Voest EE, Benezra R, Kerbel RS (2008) Rapid chemotherapy-induced acute endothelial progenitor cell mobilization: implications for antiangiogenic drugs as chemosensitizing agents. Cancer Cell 14(3): 263-273.

Shaked Y, Tang T, Woloszynek J, Daenen LG, Man S, Xu P, Cai SR, Arbeit JM, Voest EE, Chaplin DJ, Smythe J, Harris A, Nathan P, Judson I, Rustin G, Bertolini F, Link DC, Kerbel RS (2009) Contribution of granulocyte 
colony-stimulating factor to the acute mobilization of endothelial precursor cells by vascular disrupting agents. Cancer Res 69(19): 7524-7528.

Shojaei F, Wu X, Malik AK, Zhong C, Baldwin ME, Schanz S, Fuh G, Gerber HP, Ferrara N (2007) Tumor refractoriness to anti-VEGF treatment is mediated by $\mathrm{CD}_{11 \mathrm{~b}}{ }^{+} \mathrm{Gr1}{ }^{+}$myeloid cells. Nat Biotechnol 25(8): 911-920.

Taylor M, Billiot F, Marty V, Rouffiac V, Cohen P, Tournay E, Opolon P, Louache F, Vassal G, Laplace-Builhe C, Vielh P, Soria JC, Farace F (2012) Reversing resistance to vascular-disrupting agents by blocking late mobilization of circulating endothelial progenitor cells. Cancer Discov 2(5): 434-449.

van Laarhoven HW, Fiedler W, Desar IM, van Asten JJ, Marreaud S, Lacombe D, Govaerts AS, Bogaerts J, Lasch P, Timmer-Bonte JN, Lambiase A, Bordignon C, Punt CJ, Heerschap A, van Herpen CM (2010) Phase I clinical and magnetic resonance imaging study of the vascular agent NGR-hTNF in patients with advanced cancers (European Organization for Research and Treatment of Cancer Study 16041). Clin Cancer Res 16(4): 1315-1323.

Welford AF, Biziato D, Coffelt SB, Nucera S, Fisher M, Pucci F, Di Serio C, Naldini L, De Palma M, Tozer GM, Lewis CE (2011) TIE2-expressing macrophages limit the therapeutic efficacy of the vascular-disrupting agent combretastatin A4 phosphate in mice. J Clin Invest 121(5): 1969-1973.
Workman P, Aboagye EO, Balkwill F, Balmain A, Bruder G, Chaplin DJ, Double JA, Everitt J, Farningham DA, Glennie MJ, Kelland LR, Robinson V, Stratford IJ, Tozer GM, Watson S, Wedge SR, Eccles SA (2010) Guidelines for the welfare and use of animals in cancer research. Br J Cancer 102(11): 1555-1577.

Yang L, DeBusk LM, Fukuda K, Fingleton B, Green-Jarvis B, Shyr Y, Matrisian LM, Carbone DP, Lin PC (2004) Expansion of myeloid immune suppressor $\mathrm{Gr}^{+} \mathrm{CD}_{11} \mathrm{~b}^{+}$cells in tumor-bearing host directly promotes tumor angiogenesis. Cancer Cell 6(4): 409-421.

Zucali PA, Simonelli M, De Vincenzo F, Lorenzi E, Perrino M, Bertossi M, Finotto R, Naimo S, Balzarini L, Bonifacio C, Timofeeva I, Rossoni G, Mazzola G, Lambiase A, Bordignon C, Santoro A (2013) Phase I and pharmacodynamic study of high-dose NGR-hTNF in patients with refractory solid tumours. $\mathrm{Br} J$ Cancer 108(1): 58-63.

This work is published under the standard license to publish agreement. After 12 months the work will become freely available and the license terms will switch to a Creative Commons AttributionNonCommercial-Share Alike 3.0 Unported License.

Supplementary Information accompanies this paper on the British Journal of Cancer website (http://www.nature.com/bjc) 